\title{
O HOMEM NO VALE DO SÃO FRANCISCO: UM LEGADO DE DONALD PIERSON ÀS CIÊNCIAS HUMANAS E SOCIAIS NO BRASIL
}

\author{
Elizabeth de Melo Bomfim \\ Universidade Federal de São João Del-Rei
}

RESUMO: Um importante legado de Donald Pierson às Ciências Humanas e Sociais no Brasil é a sua obra $O$ Homem no Vale do São Francisco. Este artigo ancora-se numa reflexão sobre o autor e seu trabalho, expondo o cenário do homem no seu habitat, que constitui, parafraseando Pierson, palco de uma relação rara e clara. Ressalta, também, as principais contribuições do desenho traçado pela pesquisa realizada, pontuando os procedimentos metodológicos e alguns diálogos entre os pesquisadores e as comunidades.

PALAVRAS-CHAVE: História da Psicologia Social no Brasil; Ciências Humanas e Sociais no Brasil; Vale do São Francisco.

\section{LIFE IN A BRAZILIAN VALLEY: A LEGACY BY DONALD PIERSON TO HUMAN AND SOCIAL SCIENCES IN BRAZIL}

ABSTRACT: One important legacy left by Donald Pierson to Human and Social Sciences in Brazil is his work Life in a Brazilian Valley. This article is a reflection about the author and his work, showing man's background in his habitat, which constitutes, in Pierson's words, the stage for a rare and clear relationship. It emphasizes the main contributions of the design sketched by the research, pointing out the methodological procedures and some dialogues between researchers and communities.

KEYWORDS: History of Social Psychology in Brazil; Human and Social Sciences in Brazil; San Francisco Valley.

Região de população tenaz, onde, há pouco tempo, ergueu-se um bispo que, num inusitado ato de jejum, suspendeu, ainda que temporariamente, o desvio do percurso das águas do rio, o Vale do São Francisco foi, na década de 1950, objeto de estudo de uma equipe de cientistas sociais liderados por Donald Pierson. O projeto de pesquisa, realizado a partir de um convênio entre a Escola Livre de Sociologia e Política de São Paulo e a, então existente, Comissão do Vale do São Francisco, resultou na publicação, em 1972, da obra O Homem no Vale do São Francisco, sendo que suas 1.500 páginas foram divididas em três tomos. Trata-se de um legado que evidencia um dos momentos inaugurais de institucionalização da pesquisa em ciências humanas e sociais no Brasil, o que nos remete à orientação metodológica e ao desenho do projeto.

A obra que traz à memória as características de uma gente e de uma região marcadas por violentas raízes históricas, incluindo o extermínio de inúmeros indígenas, constitui, ainda hoje, um marco referencial para estudo e análise do homem e da região do Vale do São Francisco. A relevante contribuição de Pierson nos faz defrontar com a relação do homem com sua cultura e seu ambiente, em suas bases históricas, ecológicas e psicossociais, e entender os mecanismos de sobrevivência da forte gente sertaneja.

A região é marcada pelas águas do rio São Francisco, águas que brotam na Serra da Canastra em São Roque de Minas (MG), num local de mananciais que convidam a um toque para o suave sentir de sua frieza. Águas que, acrescidas pelos sucessivos afluentes, vão agregando volume ao rio e proporcionando-lhe a força de suas sucessivas cachoeiras: Cachoeira Grande, Cachoeira de Pirapora, Cachoeira de Sobradinho, Cachoeira de Itaparica e a altíssima Cachoeira de Paulo Afonso. O rio deságua em terras alagoanas, depois de atravessar os Estados da Bahia, Pernambuco e Sergipe, deixando preciosas dádivas no seu percurso.

O rio São Francisco, outrora denominado de Opara pelos índios e cujo descobrimento é atribuído a Américo Vespúcio, que o teria navegado em 1501, é um rio de curso lento que delimita um vale, o Vale do São Francisco. E foi nesse vale que a população respondia ao pesquisador visitante que, chegando à porta da casa, deveria chamar:

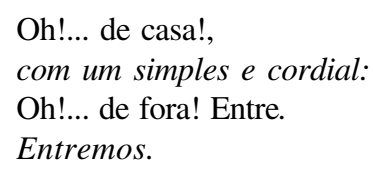

\section{O Desenho do Projeto e as Questões Metodológicas}

O Homem no Vale do São Francisco espelha um autor versado nas ciências humanas e sociais, seguro e maduro. Na época da publicação da obra no Brasil, Pierson tinha 72 anos de idade e, na sua bagagem, trazia sua graduação com especialidade em Psicologia, Letras e História, um mestrado e um Ph.D. em Sociologia e Antropologia Social, na Universidade de Chicago. Seu orientador, Robert Park, e seus professores da Universidade de Chicago, George Herbert Mead, Ernest W. Burgess, Robert Redfield, Herbert Blumer, William F. Ogburn e o inglês A. R. RadcliffeBrown, marcaram sua formação intelectual e ampliaram seu campo de trabalho, fornecendo-lhe instrumentais de pesquisa e de ensino. 
É importante assinalar que a Universidade de Chicago, principal centro americano de ciências sociais na época, desenvolvia pesquisas relevantes nos campos da Sociologia, da Antropologia, da Psicologia Social e da Ecologia Humana.

Durante a realização de seu doutorado, Pierson esteve no Brasil, por um período de 22 meses, entre 1935 e 1937, sob os auspícios da Social Science Research Committee da Universidade de Chicago e da Rosenwald Fund. Nessa sua primeira estada, dirigiu-se ao Estado da Bahia para a realização de uma pesquisa sobre relações raciais. Da pesquisa resultou a publicação do livro Negroes in Brazil: A Study of Race Contact at Bahia, editado em 1942. A obra foi vencedora do prêmio Anisfield, na categoria de melhor livro científico do ano no campo das relações raciais.

Em 1935, Pierson foi convidado, pelo então diretor Cyro Berlinck, para lecionar Psicologia Social, Sociologia e Antropologia Social na Escola Livre de Sociologia e Política de São Paulo (ESP). Retornando ao Brasil, tornou-se uma espécie de diretor acadêmico da ESP, tendo realizado e supervisionado diversas pesquisas científicas, dirigido o Departamento de Sociologia e Antropologia e criado, em 1941, a Divisão de Estudos Pós-Graduados, que deu origem à Escola Pós-Graduada da Escola Livre de Sociologia e Política. Com seus auxiliares, foi responsável pela tradução de vários trechos de obras e de artigos científicos, chegando a constituir um conjunto formado por 220 textos, denominado por ele de Leituras de Sociologia e Antropologia Social.

Pierson encontrou na ESP, que havia sido fundada em 1933 em resposta à demanda de modernização em São Paulo, um clima propício para a formação de cientistas sociais interessados em mudanças no panorama sociopolítico.

Com a chegada de Donald Pierson, a ESP torna-se uma instituição importante na divulgação, no Brasil, das idéias e propostas científicas desenvolvidas na "Escola de Chicago", e para lá se dirigem estudantes de várias regiões do país, entre eles Florestan Fernandes, Oracy Nogueira, Darcy Ribeiro, Levy Cruz, Mário Wagner Vieira da Cunha e Juarez Brandão Lopes.

No começo da década de 1950, Pierson, com seus colaboradores, inicia, a partir de um exaustivo levantamento bibliográfico, o Projeto do São Francisco, nome atribuído ao convênio assinado entre a Escola Livre de Sociologia e Política e a antiga Comissão do Vale do São Francisco. O projeto tinha duplo objetivo: o treinamento de estudantes da ESP nos métodos e técnicas de pesquisa no campo e o estudo da cultura brasileira.

Após dois meses de viagem desde a nascente até a foz do rio São Francisco para inquéritos preliminares, Pierson e seus colaboradores diretos, Octavio da Costa Eduardo e Levy Cruz, escolheram cinco diferentes áreas como amostras para a realização de estudos mais sistemáticos sobre a vida ecológica e social. As áreas escolhidas eram: 1) de criação de gado, 2) influenciada pela pesca, 3) de afloramento de calcário, 4) de caatinga com criação de cabras e 5) de cultivo de arroz. Dessa viagem resultou a publicação, em co-autoria, do artigo Hipóteses e sugestões sobre o ensino no Vale do São Francisco (Pierson et al., 1952).

Para os estudos mais sistemáticos, a equipe contou com a participação de 22 pesquisadores, entre eles Alceu Maynard Araújo, Alfonso Trujillo Ferrari, Esdras Borges Costa, Fernando Altenfelder Silva, Levy Cruz e Octávio da Costa Eduardo.

Em 1959, com auxílio financeiro da Fundação Rockfeller, Pierson retorna ao Brasil e faz, pessoalmente, a entrega dos manuscritos ao Diretor-Superintendente da, então, Comissão do Vale do São Francisco, que foi, após o golpe de 1964, transformada em Superintendência do Vale do São Francisco (SUVALE). Nessa ocasião, dirigese ao Vale do São Francisco, para sanar dúvidas ocorridas durante o preparo do manuscrito. Em 1972, após 13 anos sob a tutela da SUVALE aguardando oportunidade para editoração, a obra é, finalmente, publicada no Brasil.

O exaustivo estudo empírico retrata, em cada uma das cinco áreas, duas localidades diferentes: uma, marcada pela vida em moldes tradicionais, ligada em grande parte ao passado, e, a outra, marcada pelo contato mais freqüente com o mundo exterior. Em todas as localidades foram realizadas observações sistemáticas e entrevistas durante um período não inferior a seis meses e o resultado foi um exaustivo relato de dados empíricos.

O estudo empírico, que prioriza um olhar para a realidade em detrimento de generalizações de grandes vultos, era, para Pierson, a maneira mais adequada ao caráter de um campo científico ainda recente. O estágio de desenvolvimento das ciências sociais só permitiria ao cientista uma reflexão, quer descritiva, quer analítica, do seu objeto de estudo, devido à dificuldade de um empreendimento explicativo. Assim, caberia ao cientista social, sobretudo, a utilização dos procedimentos descritivos e analíticos da realidade estudada.

\footnotetext{
...o cientista social busca tão somente descrever e analisar a realidade e, às vezes, se possível - o que constitui empreendimento muito mais difícil em virtude do caráter ainda pioneiro de nossa disciplina - explicá-la. Ao contrário de outros especialistas, que usam procedimentos próprios e talvez inteiramente legítimos, o cientista social, para seguir fielmente os cânones de sua profissão, nem aprova nem desaprova, nem admira nem critica, nem elogia nem reprova, nem enaltece nem condena. Ao contrário, retrata simplesmente, de modo tão simples e compreensível quanto possível, o que parece ser a realidade social sob observação. (Pierson, 1972, Prefácio, v. III, p. VIII-IX)
} 
Para levar a cabo tal projeto seria necessário deixar, às comunidades estudadas, a orientação mais específica da pesquisa, e os pesquisadores, na tentativa de melhor conhecê-las, não deveriam levar, a priori, qualquer esboço teórico ou analítico de compreensão da vida local. Era imprescindível, contudo, que os pesquisadores, na relação dialogante, registrassem palavras e expressões utilizadas pelos pesquisados. Algumas delas foram registradas na obra de Pierson com o propósito de fornecer um quadro mais vivo e dramático da realidade:

\section{... a fim de expor mais vívida e, às vezes, mais dramati- camente ao leitor a realidade descrita e analisada, são citadas palavras realmente pronunciadas pelos informantes. Deve ficar claro, no entanto, que isto se faz meramente para esclarecer um ponto. De modo algum a citação de determinada observação indica ter ela merecido a aprovação ou desaprovação do cientista social. (Pierson, 1972, Prefácio, tomo III, p.IX)}

A partir do desenho delineado por Pierson, com o arcabouço metodológico proposto e as orientações na condução do projeto de pesquisa, os pesquisadores embrenharamse pelas veredas dos sertões em busca de dados sobre as comunidades e sobre a vida do homem no Vale do São Francisco.

\section{O Homem no seu Habitat e Alguns Diálogos Relevantes}

As circunstâncias geográficas da região são analisadas através dos estudos sobre a base física, o clima, o abastecimento de água, a vegetação e os animais nativos da região. Alvitradas as relações do homem com o meio físico pelo processo demográfico e pelo substrato econômico indispensável à sua existência, as conjunturas geográficas remetem ao passado nesse ambiente e à vida associativa e cultural na região.

Das circunstâncias geográficas salta-se às históricas de uma região marcada pelos traços delineados pelos primeiros habitantes - indígenas de diversos grupos étnicos - que entram em contato, sangrento ou não, com os iniciais desbravadores. Seguem-se os marcos históricos dos grandes fazendeiros e, posteriormente, dos bandeirantes audaciosos e intrépidos. Das raízes desse passado ficaram os traços dos conflitos raciais e das volumosas concessões de terras para as grandes fazendas, expressos nos exuberantes exemplos da Casa da Torre e da Casa da Ponte. As missões e os missionários, os povoamentos, a corrida às minas gerais em busca do ouro, a presença dos holandeses e, por fim, os remanescentes indígenas revelam um passado de resistências do homem sertanejo.

E os olhares voltam-se para as características gerais da população do Vale do São Francisco que ocupava o espaço físico, principalmente em função do solo, do clima e do suprimento de água. Habitando nas escassas cidades, nos povoados, nas sedes ou nos retiros das fazendas, a população passa a ser descrita segundo sua distribuição por sexo, idade, raça e nacionalidade. Acrescentam-se as análises da fertilidade, longevidade e mortalidade e o estudo da mobilidade dentro, fora e através das comunidades e pelas migrações.

Nos delineamentos da alimentação e dos hábitos alimentares, vê-se a análise das bebidas, do preparo dos alimentos, das refeições e dos cardápios, dos hábitos de comer, das proibições alimentares e do uso do fumo e da maconha. A maconha era utilizada, em geral, nas classes mais baixas da população na região em torno da Passagem Grande. Conhecida como fumo-de-angola, possivelmente pelo fato de se constar que teria sido trazida pelos escravos africanos, era fumada com uma espécie de:

narguilê primitivo, composto de uma garrafa comum, de boca estreita, cheia de água e o canudo do cachimbo de maconha, conhecido como Marica, mergulhado no líquido. As sumidades floridas da maconha são colocadas no fornilho de barro do cachimbo $e$ acesas com um fósforo. O fumo é lavado, dizem os moradores, pelo reservatório de água antes de chegar à boca do fumante. (Pierson, 1972, Vol. II, p.95)

A maconha era fumada em grupo, com as pessoas em círculo passando de mão em mão o cachimbo e dizendo Ajoeie, Marica! E, para exaltá-la, era entoada uma canção conhecida como Lôa.

Era uma experiência social compartilhada, assim como compartilhadas eram as idéias e as práticas populares relativas ao tratamento de doenças. Doenças que eram nomeadas e explicadas com termos e idéias populares. Doenças cujos tratamentos eram buscados tanto nos curandeiros, nos farmacêuticos ou nos benzedores quanto nas orações. Doenças que, ao longo da história, possibilitaram à população reunir uma longa lista de plantas consideradas curativas e consumidas com objetivos medicinais.

E o olhar se detém sobre a existência de vidas ainda bastante primitivas, com famílias dormindo no chão. Famílias com hábitos corporais diversos, entre eles o hábito ameríndio de acocorar-se sobre os tornozelos.

Na relação do homem com seu sistema ecológico, a análise volta-se para as formas gerais de sustento, abrangendo a divisão do trabalho, o uso da terra, as atividades coletoras, a criação de animais, a agricultura, o artesanato, os processos de beneficiamento, as indústrias leves, o transporte e os pesos, medidas e outros padrões utilizados. Uma divisão do trabalho esboçada pelas diferentes profissões, pelas distinções de sexo e pelas diferentes faixas etárias. $\mathrm{O}$ uso da terra avaliado pelo tamanho de propriedades, pelas fazendas e sítios existentes, pelos direitos de seu uso, pelo olhar que detecta a ausência dos proprietários e pelos sistemas de arrendamento. 
Um sistema ecológico que favorece as atividades coletoras. Atividades angariadas nas matas, com as coletas de fibras do buriti e do tucum, do coco, da palmeira de babaçu, da madeira, da taquara para os forros de casas e cercas, da paina para exportação, dos cipós, etc. Atividades coletoras diversas que incluíam as frutas nativas, o mel silvestre, a caça, a pesca, a fibra de caroá, a cera de carnaúba, a borracha silvestre, o cristal, o ouro e os diamantes, o sal e o salitre.

As criações do gado bovino, das cabras, dos carneiros, dos animais de carga e de montaria que se revezavam com as atividades de agricultura, descritas nas lavouras, no calendário agrícola, nas plantações, nas capinações e nas colheitas, nas hortas, nos pomares e nos jardins existentes, na irrigação, no mutirão, nas pragas e nos outros prejuízos ocorridos.

$\mathrm{O}$ artesanato traz à baila as atividades de fiação e de tecelagem responsáveis pelas redes de pescar, pelos cobertores, pelas redes para deitar, pelas esteiras, pelas cordas, pelos cestos, pelos chapéus de palha e pela beleza das rendas de bilros. No artesanato figuram, também, os trabalhos em couros, a cerâmica, a carpintaria e a marcenaria.

Nos processos de beneficiamento, vêem-se o curtimento, a limpeza e a secagem do peixe, a secagem da carne ao sol, os laticínios, o preparo da farinha de mandioca e outras farinhas, o beneficiamento da cana-de-açúcar, da fibra de caroá e da cera de carnaúba, a feitura de tijolos e de telhas, o descaroçamento do algodão, o fabrico do carvão vegetal e do sabão.

O transporte, quer o fluvial realizado por canoas, barcas, barcos à vela, vapores, lanchas a motor e balsas, quer o terrestre, desde a locomoção a pé, os bois e carros-de-boi, os animais de carga e de montaria, os veículos a motor e a estrada de ferro, foi registrado. E é interessante notar que o pesquisador, integrando-se ao ambiente, torna-se protagonista de sua análise, como que nos lembrando os antigos viajantes, e registra suas aventuras:

o "Raul Soares", que na ocasião em que o autor nele viajou era de propriedade da Navegação Mineira do São Francisco, conduzia duas classes de passageiros, como, aliás, os outros grandes vapores. Havia camarotes para os de primeira classe e lugares no tombadilho superior para as redes dos de segunda. (Pierson, 1972, v. II, p. 569)

E, assim, Pierson registra uma população que mantinha, com seu habitat, uma clara relação:

É rara no Brasil uma relação tão clara como a que existe entre o homem e o habitat no Vale do São Francisco, fato este que se reflete na densidade da população, na natureza seminômade da ocupação humana, antes do contato com os europeus e nas gerações sucessivas, e na economia prevalecente no passado e que ainda predomina na maior parte da região. (Pierson, 1972, Vol. III, pp. 449-450)
Para além da ordem ecológica, a ordem social e a ordem cultural da região do Vale do São Francisco foram analisadas. A etiqueta, os laços de parentesco e de compadrio, os rituais, as cerimônias e as crenças aliavam-se, na sequiência, aos ciclos de vida e de morte e ao comportamento político, registrado num frequiente ato de distração geral, principalmente, entre adultos, de "conversar política".

A etiqueta, que, segundo Pierson, seria responsável pelo tom das relações sociais, foi entendida como forma de comportamento exigida pela boa educação ou pela convenção. Incluía a cortesia, a polidez, a civilidade e a capacidade de mostrar-se obsequioso e atencioso para com os demais. Pierson, reconhecendo a raridade de estudos sobre etiqueta, afiançava que ela é uma das formas mais poderosas de controle social.

Ressaltando o alto grau de cortesia, de polidez e de hospitalidade das pessoas do Vale do São Francisco, inclusive nas famílias de classe econômica mais baixa, a menção era dirigida ora para a gentileza dos convites aos recémchegados, que incluía uma refeição em casa ou uma visita à fazenda, ora para o convite entre amigos e conhecidos para beber rum, cerveja ou até mesmo um cafezinho. Marcados traços de uma etiqueta que não deixava de lado as saudações com o aperto de mãos entre conhecidos ou com um abraço entre amigos ou parentes. E mais ainda, a cortesia do anfitrião, que, diante da ameaça do visitante de se retirar de sua casa, sempre respondia:

Ainda é cedo!

Cortesia presente, outrossim, no quase extinto gesto de usar versos nas saudações e despedidas entre amigos. Versos dirigidos até aos pesquisadores:

Adeus! Amigo querido!
Lembre-se sempre de mim!
Um firme amô qu'eu te tenho
Só por morte terá fim
(Pierson, 1972, Tomo III, p.16)

E o homem do Vale do São Francisco, marcado pela cortesia, pela polidez, pela hospitalidade e pela liberalidade, ridicularizava e condenava a descortesia, a falta de polidez, de hospitalidade e a avareza. Homem sertanejo que matinha o hábito de pedir bênção aos pais, aos parentes mais velhos e aos padrinhos, assim como o uso de expressões como Senhor, Doutor e Coronel, para se dirigir às pessoas de condição social mais alta.

Gente que tinha expectativa de receber presentes em pagamento a um favor ou de padrinhos, ou no dia do casamento, ou do nascimento de crianças, e que preservava o hábito de levar presentes nas visitas às pessoas de outras cidades. Gente cuja estrutura familiar era constituída por três tipos de família: o tipo conjugal - família nuclear estabelecida por meio de casamento formal ou de sanção 
social -, o tipo de grupos de parentesco - constituído pela família nuclear e os parentes mais próximos - e o tipo de compadrio - sendo ainda maior, incluía todos os parentes conhecidos e as relações entre padrinhos e afilhados.

Uma população essencialmente católica, mas convivendo com protestantes, maçons e espíritas numa região de considerável sincretismo religioso, com a existência do candomblé, do toré e de seitas incipientes. Região que abrigou a experiência comunitária de Canudos. Região de população católica que respeitava os dias e os lugares considerados sagrados (oratórios, igrejas, capelas, cruzeiros e cemitérios) e dava guarita aos funcionários católicos (padres, vigários acólitos, sacristãos, etc.). População marcada pela existência dos penitentes, dos ermitões andarilhos, das confrarias religiosas, das peregrinações, dos votos, das oferendas votivas, das missas, das rezas, das novenas e das festas religiosas, sendo as que mais atraíam participantes as de Bom Jesus do Matosinhos (Congonhas, na extremidade sul da bacia do São Francisco) e as de Bom Jesus da Lapa (na Bahia). População que cultivava as festas juninas, as festas de São Gonçalo, as festas do Divino, as cavalhadas e os bailes pastoris.

E toda a dramaticidade da ordem social, mais uma vez, remete à clara relação do homem com o Vale do São Francisco. Um homem que não quer ser esquecido tal como nos versos de despedida da idosa rendeira:

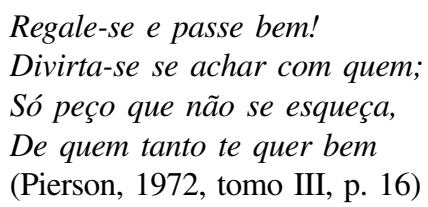

\section{Considerações Finais}

Pierson faleceu em 1995, mas sua obra continua sendo uma das mais importantes referências para a compreensão da vida no Vale do São Francisco. Referência reconhecida não só pela CODEVASF - Companhia de Desenvolvimento dos Vales do São Francisco e Parnaíba -, a substituta da SUVALE, mas pelos pesquisadores das Ciências Humanas e Sociais no Brasil.

O legado de Pierson tem sido reconhecido por diferentes gerações de cientistas humanos e sociais no Brasil, e seus trabalhos, ainda hoje, são citados e/ou estudados na Sociologia (Mendoza, 2005), na Antropologia (Corrêa, 1987; Peixoto, \& Simões 2003) e na Psicologia Social (Bomfim, 2003, 2004).

Suas contribuições para a Psicologia Social, entendida por ele como um subcampo tanto da Sociologia quanto da Psicologia, remetem não só ao fato de ter sido um dos pioneiros professores de Psicologia Social no Brasil, mas também ao seu legado registrado em suas publicações. Um legado que reflete um investigador social atento à coleta sistemática de evidências empíricas e à divulgação dos procedimentos metodológicos. Um legado relevante ao momento de inauguração da institucionalização da pesquisa social no país.

Donald Pierson registrou, em sua busca de uma visão mais íntima e uma compreensão mais profunda da vida dos pesquisados, um olhar para uma realidade regional brasileira que traz à tona o homem no seu habitat, atravessado pelas suas relações sociais e políticas, com sua inserção comunitária e ecológica e interagindo com os pesquisadores.

\section{Referências}

Bomfim, E. (2003). Psicologia Social no Brasil. Belo Horizonte: Edições do Campo Social.

Bomfim, E. (2004). Históricos cursos de Psicologia Social no Brasil. Psicologia \& Sociedade, 16(2), 32-36.

Corrêa, M. (Ed.) (1987). História da Antropologia no Brasil (19301960). Campinas: Ed. da UNICAMP/Edições Vértice.

Mendoza, E. (2005). Donald Pierson e a escola sociológica de Chicago no Brasil: os estudos urbanos na cidade de São Paulo (19351950). Sociologias, 14, 440-470.

Peixoto, F. \& Simões, J. (2003). A Revista de Antropologia e as ciências sociais em São Paulo: notas sobre uma cena e alguns debates. Revista de Antropologia, 46, 383-409.

Pierson, D. (1942). Negroes in Brazil: a study of race contact at Bahia. Chicago: University of Chicago Press.

Pierson, D. (1972). O Homem no Vale do São Francisco. Rio de Janeiro: SUVALE.

Pierson, D., Eduardo, O. \& Cruz, L. (1952). Hipóteses e sugestões sobre o ensino no Vale do São Francisco. Revista Brasileira de Assuntos Pedagógicos, XVII(46), 22-37.

Elizabeth de Melo Bomfim é membro do Laboratório de Pesquisa e Intervenção Psicossocial da Universidade Federal de São João Del Rei, foi Presidente da Associação Nacional de Pesquisa e Pós-Graduação em Psicologia ANPEPP - (1994-1996), Presidente da Associação Brasileira de Psicologia Social - ABRAPSO - (19871989 e 1997-1998), Pesquisadora Visitante da UFSJ com bolsa da FAPEMIG (2003-2005) e Coordenadora do Programa de Pós-Graduação em Psicologia da UFMG (1991-1994). O endereço para correspondência é: Praça Dom Helvécio, 74. Dom Bosco. 36301160 São João Del Rei, MG - Brasil. embomfim@brfree.com.br

O Homem no Vale do São Francisco: Um Legado de Donald Pierson às Ciências Humanas e Sociais no Brasil

Elizabeth de Melo Bomfim

Recebido: 18/01/2006

Aceite final: 26/04/2006 